\title{
Spatio-temporal analysis of the progression of Aujeszky's disease virus infection in wild boar of Saxony-Anhalt, Germany
}

\author{
Nicolai Denzin ${ }^{1}$, Joachim Borgwardt ${ }^{1}$, Conrad Freuling², Thomas Müller ${ }^{2}$ \\ ${ }^{1}$ State Office for Consumer Protection Saxony-Anhalt, Department of Veterinary Medicine, Stendal, Germany; \\ ${ }^{2}$ Friedrich-Loeffler Institut, Federal Research Institute for Animal Health, Institute of Molecular Biology, \\ Greifswald - Insel Riems, Germany
}

\begin{abstract}
Aujeszky's disease (AD, pseudorabies) is a notifiable disease caused by Suid herpesvirus 1 (SuHV-1), also named pseudorabies virus $(\mathrm{PrV})$. The study aimed at determining the occurrence and spatio-temporal trend of specific antibodies to $\mathrm{AD}$ virus (ADV) among wild boar of Saxony-Anhalt, a landlocked federal state situated in the western part of eastern Germany. To this end, a total of 7,209 blood samples were collected and tested from 2000 to 2011. An average seroprevalence of $6.8 \%$ was found for the entire observation period, whilst seroprevalence increased significantly between time periods January 2000-March $2009(\mathrm{n}=3,605$; prevalence $=4.5 \%)$ and March 2009-December $2011(\mathrm{n}=3,604$; prevalence $=9.1 \%$ ). Spatial analysis revealed an extremely heterogenous distribution of seropositive samples with cluster formation [relative risk $(\mathrm{RR})$ up to $41, \mathrm{P}=0.001$ ] in the east. A comparison of spatial clusters between the aforementioned time intervals showed an expansion of the disease in the north to north-westerly direction. A test for spatial shift involving the entire territory of Saxony-Anhalt detected a spread of ADV infection in the latter direction $(\mathrm{P}=0.079)$ at the average speed of $3.3 \mathrm{~km} /$ year. Detailed study of the distribution and spread of the disease among wild boar, including assessment of the speed of spatial spread, has not been done in the region before. Saxony-Anhalt has been officially recognised as being free of AD in domestic pigs since 1996. Despite increasing ADV seroprevalences in the wild boar population of Saxony-Anhalt and other federal states in the east of Germany, no spill-over to domestic pigs have been reported. The currently implemented monitoring will be continued in conjunction with surveillance of classical swine fever (CSF) to further trace ADV infections in the wild boar population of Saxony-Anhalt.
\end{abstract}

Keywords: spatio-temporal analysis, spatial shift, Aujeszky's disease, seroprevalence, veterinary epidemiology, Germany.

\section{Introduction}

Aujeszky's disease (AD, pseudorabies) is a notifiable disease caused by Suid herpesvirus 1 [SuHV1, syn. Pseudorabies virus (PrV) or Aujeszky's disease virus $(\mathrm{ADV})]$, which belongs to the family Herpesviridae, subfamily Alphaherpesvirinae, genus Varicellovirus (Mettenleiter, 2000). Members of the family Suidae (true pigs) are the only natural hosts for ADV although the virus can infect other species as well, including cattle, sheep, dogs, cats and rats, causing fatal disease (Pensaert and Kluge, 1989). In particular, carnivores can easily become infected by the oral route via direct contact or consumption of ADV contaminated meat and are often indicators for the presence of

Corresponding author:

Nicolai Denzin

State Office for Consumer Protection Saxony-Anhalt

Department of Veterinary Medicine

Haferbreiter Weg 132-135, 39576 Stendal, Germany

Tel. +49 393163 1463; Fax +49 3931631103

E-mail: Nicolai.Denzin@lav.ms.sachsen-anhalt.de
ADV on pig farms. Generally, the disease has a worldwide distribution, particularly in regions with dense populations of domestic pigs, and represents one of the most dangerous domestic animal diseases because of the substantial economic losses it might cause the pig industry. However, in recent decades $\mathrm{AD}$ has been virtually eliminated from domestic pigs in several parts of the world due to increased control efforts and the strict implementation of national elimination programmes that usually relied on large-scale vaccination with attenuated or gE-deleted vaccines (Mettenleiter et al., 2012). The latter vaccine also allows diagnostic discrimination of antibody titres triggered by infection from those induced by vaccination (the so-called "DIVA strategy" that allows "differentiating infected from vaccinated animals"). In Europe, using this strategy, ADV has been eliminated from domestic pig populations in Austria, Cyprus, the Czech Republic, Denmark, Finland, France (except single departments), Hungary, Luxembourg, the Netherlands, Sweden, Switzerland, Slovakia and Great Britain (England, Scotland and Wales) (Pannwitz et al., 2012). In Germany, nationwide elimination of $\mathrm{AD}$ was 
achieved in 2003 (Müller et al., 2003). In countries officially recognised as $\mathrm{AD}$-free according to criteria of the World Organization for Animal Health (OIE), vaccination against $\mathrm{ADV}$ is prohibited. $\mathrm{AD}$ is still endemic in Eastern and South-Eastern Europe (Pannwitz et al., 2012).

Whilst there has been tremendous progress towards control and elimination of the disease in domestic pigs, ADV infections seem to be widespread and even increasing in populations of non-domestic swine, including feral pigs, wild boar and hybrids, across the world (Pannwitz et al., 2012). The first evidence for the occurrence of ADV in wild swine was reported from the USA, Italy, the former Yugoslavia and The Netherlands in the mid-1980s (Müller et al., 2000). In recent years, $\mathrm{ADV}$ infections in wild boar populations have also been reported from additional European countries including the Czech Republic (Sedlak et al., 2008), France (Albina et al., 2000), Slovenia (Vengust et al., 2006), Croatia (Zupanic et al., 2002; Roic et al., 2012), Poland (Szweda et al., 1998), Russia (Shcherbakov et al., 2007), Switzerland (Leuenberger et al., 2007), Spain (Gortázar et al., 2002; Boadella et al., 2012) and Austria (Steinrigl et al., 2012). It is supposed that variants of ADV have found ecological niches in populations of wild boar, or that wild boar populations represent the actual historical reservoir for the virus (Müller et al., 2000).

Knowledge regarding the occurrence of ADV infections in Germany is patchy. Only limited information is available with respect to ADV infections in wild boar in the western states of the country. Recently, an ADV seroprevalence of $4.2 \%$ was found in 94 shot wild boars from hunting regions in the federal states of Bavaria, Rhineland-Palatinate and BadenWürttemberg (Sattler et al., 2012). East Germany, in contrast, has been intensively studied. Already in 1985, an annual, area-wide serological monitoring of the wild boar population and central data collection was laid down in national decrees and implemented in the former German Democratic Republic (Anonymous, 1987). When with the re-unification of the two German states in 1990 the animal health legislation in East Germany changed, serological monitoring of wild boar populations has been no longer mandatory but rather conducted on a voluntary basis. However, serological surveys from the north-eastern federal states of Brandenburg and MecklenburgWestern Pomerania provided evidence for local ADV seroprevalences up to $25 \%$ (Oslage et al., 1994; Müller et al., 1997, 1998a; Thulke et al., 2005; Kaden et al., 2009). It was only recently that, in a supra- regional approach, a comprehensive descriptive longterm epidemiological analysis of ADV infections in wild boar populations in East Germany comprising six federal states was presented (Pannwitz et al., 2012). The study, using a reference period of 1985-2008, suggested a continuing spread of the infection in a western direction; however, despite the huge sample size the data set was fragmented, which prevented a sophisticated spatial analysis.

The main objective of this study was to evaluate the spatio-temporal trend of ADV infections in the wild boar population in East Germany in more detail, taking Saxony-Anhalt as an example and model for a potential nationwide analysis which might become feasible with improved data availability in future. By using advanced spatial analysis tools, we intended to (i) draw statistical inferences as to geographical clustering of ADV infections; (ii) determine the direction and speed of spread of the infection in the wild boar population; and (iii) minimize the impact of sample origin as a source of selection bias in comparing seroprevalences over time. The results of this study may influence sample size considerations in the monitoring of ADV infection in wild boar in Saxony-Anhalt and increase the awareness as regards the biosecurity measures of pig holdings particularly in high-risk areas. Additionally, federal states not yet systematically monitoring the disease among wild boar might consider the implementation of monitoring programmes.

\section{Materials and methods}

\section{Study area}

Saxony-Anhalt (geographical location $50^{\circ} 56^{\prime}$ to $53^{\circ}$ $02^{\prime} \mathrm{N}$ latitude and $10^{\circ} 34^{\prime}$ to $13^{\circ} 11^{\prime} \mathrm{E}$ longitude) is a landlocked federal state of Germany situated in the western part of eastern Germany (Fig. 2). It comprises 14 districts and independent cities, 219 municipalities and 3,236 smaller administrative subunits (settlement areas) covering an area of $20,446 \mathrm{~km}^{2}$.

\section{Sampling}

Data analysed in this study were derived from a long-term serological survey within the framework of classical swine fever (CSF) and AD monitoring of wild boar populations in Saxony-Anhalt conducted between 2000 and 2011. Blood samples of wild boar were obtained during annual hunting activities and submitted by members of local hunting associations or 
by state forest officers to district veterinary offices, and subsequently sent by courier to the State Office for Consumer Protection (LAV), Saxony-Anhalt, Department 4 (Stendal, Germany) for serological testing. Whilst for the time period 2001 to 2006 no sample size was established, starting in 2007 a minimum sample size of 59 samples per year and district was prescribed in each of the 14 districts (826 samples for the entire territory). This enabled detection of the disease assuming a prevalence of $\geq 5 \%$ at the $95 \%$ confidence level (Cannon and Roe, 1982). Delivery of the sera took 1 to 4 days. For all animals, data on geographical origin (subunit) and date of sampling were recorded.

\section{Diagnostics}

Prior to testing, blood samples were centrifuged at $1,000 \mathrm{~g}$ for $10 \mathrm{~min}$ and stored at $-20^{\circ} \mathrm{C}$. Subsequently, the sera were tested using an ADV-glycoprotein B (gB)-based enzyme - linked immunosorbent assay (ELISA), the IDEXX PRV/ADV gB Test (IDEXX Laboratories Inc.; Westbrook, USA) for screening. Positive sera were confirmed with an ADV-glycoprotein I (gI)-based ELISA assay, the IDEXX PRV/ADV gI Test (IDEXX Laboratories Inc.) capable of differentiating infection from vaccination. Both these ELISA assays are known to be more sensitive than the traditionally used serum neutralization test (Oren et al., 1993).

\section{Spatio-temporal analysis}

To determine potential temporal changes in the prevalence and spatial distribution of ADV infection in wild boars, the basic data set (2000-2011) was split up into two time intervals using the median of the dates of sampling as the threshold (Fig. 1). For the spatial evaluations, the geo-coordinates of the centroids of the respective administrative subunits that were reported as the origin of the individual samples were allocated to the samples as surrogates of the actual coordinates defining the place of death for each animal delivering a blood sample. To explore the distribution of all sampling locations (centroids of subunits to which at least one sample was allocated, regardless of the test result) and those locations with at least one positive sample within the territory of Saxony-Anhalt, the locations were plotted on a map using Map Explorer, a geographical information system (GIS) application developed by the Friedrich-LoefflerInstitute and available as freeware at the website (http://www.bfav.de/kartenexplorer/) (Fig. 2).

\section{Temporal evaluation of seroprevalence}

Seroprevalence estimates were calculated for the whole study period as well as for the two time intervals defined above. As a simplification, a perfect test assumption was made and thus the seroprevalences were assumed to be estimates of the true ones with

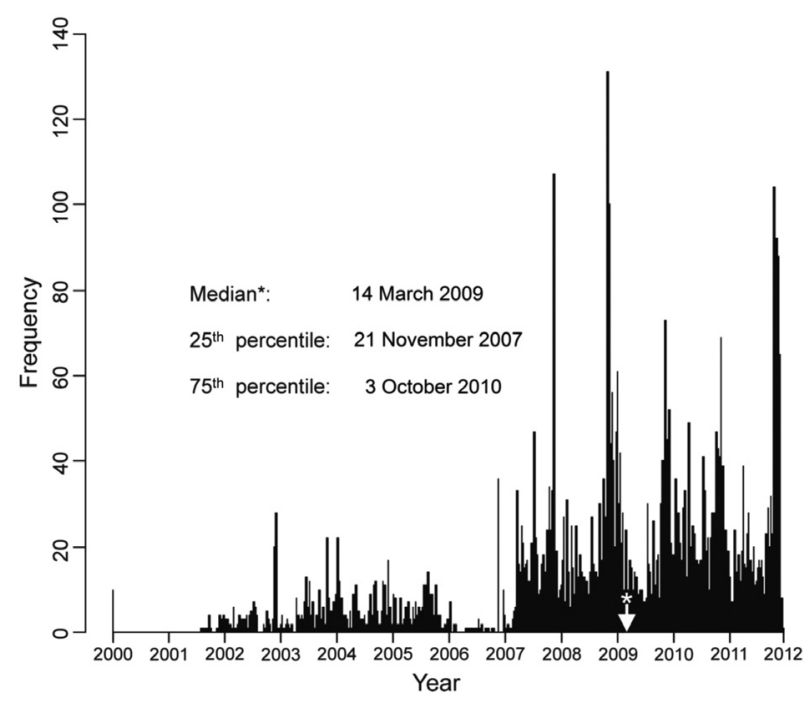

Fig. 1. Frequency distribution of the dates of sampling between 2000 and 2011.

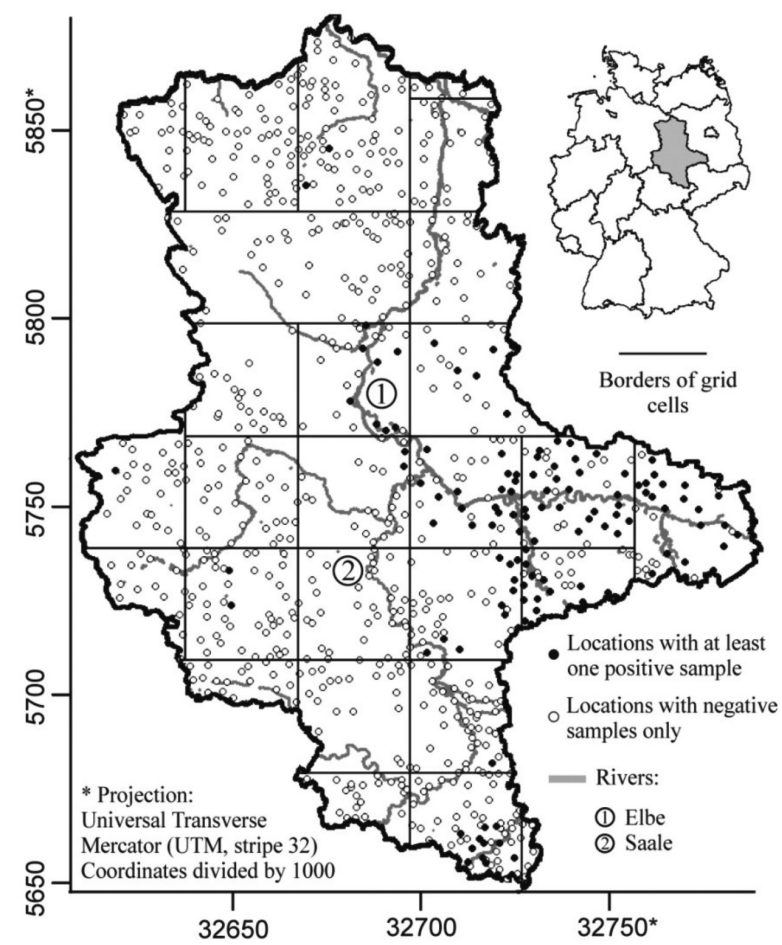

Fig. 2. Distribution of positive and negative sampling locations (centroids of subunits) from which wild boar were submitted for testing and spatial segmentation of the study area (2000-2011) using a grid overlay with a cell size of $30 \times 30 \mathrm{~km}$. 
confidence limits calculated based on the classical calculation of the confidence limits of a proportion (Petrie and Watson, 2006). For comparison, the seroprevalences of the two time intervals were additionally determined using a censored and adjusted dataset. The latter was primarily created to assess the spatial spread of ADV (details below) and reduce the bias in the prevalence estimates related to the geographical origin of the underlying samples through a stochastic adjustment of sample densities (see below) in the study area. Seroprevalence estimates for both time intervals were calculated as the arithmetic mean and the confidence interval $(\mathrm{CI})$ derived from the $2.5^{\text {th }}$ and $97.5^{\text {th }}$ percentiles of the respective seroprevalences in 10,000 iterations.

\section{Spatio-temporal evaluation of relative risk}

The approximated relative risk (RR) of a wild boar within the area of Saxony-Anhalt being seropositive for ADV was calculated and illustrated according to Davies et al. (2011) for time intervals 1 and 2, respectively. Using this method (Gaussian kernel, bandwidth chosen as fix) (Silverman, 1986), kernel density estimations of cases (i.e. seropositive wild boar) as well as of all samples (i.e. all wild boar samples regardless of test result, the basic dataset) were calculated separately for a grid overlay with a cell size of $250 \times 250 \mathrm{~m}$ for the area of Saxony-Anhalt. The ratios of the integrals of standardised kernel densities of cases and all samples in each grid cell were used to visualise the function of RR (Bithell, 1990, 1991). The bandwidth of kernel density estimations $(7.5 \mathrm{~km}$ for both intervals) was determined using a leastsquares cross-validation approach according to Bowman and Azzalini (1997). The same bandwidth was used for interpolation of cases as well as all samples (Diggle et al., 1995), with an edge correction performed as proposed previously (Diggle, 1985). Regions with significantly increased RR were detected and highlighted by calculating P-value contour lines as described by Hazelton and Davies (2009). Calculations were performed using the " $R$ " packages map tools, "sm" and "sparr" in R 2.12.2 (R Development Core Team, 2011). Additionally, to assess spatial clustering, a spatial scan statistic $\left(\mathrm{SaTScan}^{\mathrm{TM}}\right.$ ) was used (Kulldorf and Nargawalla, 1995). Because seropositive and seronegative wild boar represented cases and controls, respectively, the Bernoulli model was chosen when running the scan statistic. The scan window of the scan statistic was defined as elliptic and no overlapping was allowed, which means that so-called secondary clusters would not be reported by the software if there was overlapping with primary clusters (i.e. clusters with smaller P-values than the secondary clusters). As recommended (Kulldorf et al., 1998), the maximum window size was set to capture up to $50 \%$ of the events (cases and controls). This was done because if clusters of excessive risk and larger than $50 \%$ of the events (assuming a homogeneous distribution of events) were detected, they would anyway be better viewed as representing an area typical of the study region with a cluster of lower risk outside the scanning window.

\section{Spatial shift analysis of ADV infection}

Based on the obtained serological test results (i.e. the basic dataset), we attempted to assess a potential spatial net spread (shift) of ADV infection in the wild boar population of Saxony-Anhalt during the observation period (2000-2011). To this end, a methodology recently described for Echinococcus multilocularis (Denzin et al., 2012) was applied, i.e. we investigated if the spatial centroid (spatial mean) of disease, as determined from the co-ordinates of the positive samples in the dataset after certain adjustments (detailed below), had shifted between the two time intervals defined above. If such a shift was found, the direction was determined.

To assure the spatial representativeness of the approach for the entire study area, the basic dataset was spatially segmented by applying a grid overlay with an edge length of $30 \mathrm{~km}$. This overlay was modified in such a way that grid cells with extremely low sample sizes were sporadically merged, in particular on the fringes of the study area (Fig. 2). Since sample sizes of the grid cells differed considerably both within and between time intervals, each cell in each time interval was limited (censoring of data) to a standard sample density [sample size per area unit $\left.\left(\mathrm{km}^{2}\right)\right]$. To determine the latter, the lowest sample density for a grid cell irrespective of the time interval was identified and the corresponding sample size reduced by one. The sample density of that cell was then recalculated based on the reduced sample size and used to determine the permitted sample size $\left(\mathrm{n}_{\text {permitted }}=\mathrm{n}_{\text {original }}-\mathrm{k}\right)$ of all other grid cells depending on the area they covered. The reduced sample size turned out to be 36 for a standard grid cell $\left(30 \times 30 \mathrm{~km}\right.$ with 0.04 samples $\left./ \mathrm{km}^{2}\right)$ and 823 for the entire territory (from 27 grid cells altogether). As described above, the minimum value of $\mathrm{k}$ was chosen as 1 for the grid cell with the lowest original 
sample density to fulfil the criteria of bootstrapping (for significance testing, see below) (Denzin et al., 2012). On average, $\mathrm{k}$ was 103 , with a maximum of 858. To practically adjust the sample densities (between spatial segments as well as time intervals) and allow for significance testing, the following calculations were carried out in a stochastic process with 10,000 iterations:

(i) for each grid cell and each time interval a sample without replacement of the respective grid-cellspecific size $n_{\text {permitted }}$ was drawn from the respective existing test results (n) for the grid cells and the data set was thus reduced to 823 samples per time interval;

(ii) separately for both time intervals, the disease centroids were calculated based on the co-ordinates of the positive samples within the iteration (subsequently termed first-level centroids); and

(iii) then the adjusted shift vector of the iteration was derived as the difference between the first-level centroids (first-level centroid of time interval 2 minus first-level centroid of time interval 1).

As each of the shift vectors (difference-vectors) generated in the stochastic process was selected with the same probability, it was possible to in turn calculate the estimated, expected centroid ("second-level centroid") as the mean shift vector from the co-ordinates of the 10,000 differences between first-level centroids (Denzin et al., 2012). The results obtained, i.e. the relative spatial position of the null vector (no shift), the dispersion of the differences between the first-level centroids and the centroid of the latter (second-level centroid) as well as the mean shift vector, were charted. Assuming that the obtained density of the cloud of difference-vectors of first-level centroids represents a measure of the probability structure of a centroid shift of ADV infection in the wild boar population, this was used to test the null hypothesis $\left(H_{0}\right)$ that there was no centroid shift from time interval 1 to time interval 2. The local density at a specific difference-vector of the aforementioned cloud of all simulated difference-vectors was estimated as the sum of the distances of that specific difference-vector to its five nearest neighbours. The probability $p$ of the validity of the null hypothesis was determined as the rank of the density in the null vector compared to the densities (in ascending order) in the positions of all simulated difference-vectors divided by the quantity of all difference-vectors (number of iterations) (Denzin et al., 2012). All calculations were conducted using the software R 2.12.2 (R Development Core Team, 2011).

\section{Results}

\section{Prevalence estimation}

From 2000 to 2011, a total of 7,209 blood samples from wild boar were submitted for serological testing, with the majority of the samples drawn since 2007. A total of 487 sera tested positive by ELISA, indicative of ADV specific antibodies, resulting in an overall, average seroprevalence of $6.76 \%$ [95\% CI: 6.18 $7.33 \%$ ] for the whole observation period. The median of sampling dates was determined as 14 March 2009. Based on this date the basic dataset was split into two subsets representing the two time intervals, i.e. January 2000-March 2009 and March 2009December 2011, respectively (Fig. 1). The average ADV seroprevalences, estimated from the complete basic dataset as well as the censored and adjusted dataset, doubled from time interval 1 to time interval 2 , albeit seroprevalence estimates derived from the censored and adjusted dataset were slightly lower (Table 1). Whilst the CI of both approaches overlapped within both time intervals $(\mathrm{P}>0.05)$, they did not overlap between time intervals $(\mathrm{P}<0.05)$.

\section{Spatial distribution of samples}

Between 2000 and 2011, wild boar sera from 796 different sampling locations (see above) were submitted for testing. These locations were almost homogenously distributed over the study area (Fig. 2). Only in the Drömling territory, a swamp-like area in northwestern Saxony-Anhalt, was the number of sampling locations and sample submissions markedly lower than in other regions. Therefore, for spatial shift analysis in this area, two grid cells had to be merged

Table 1. Estimated ADV seroprevalences and the calculated $95 \%$ CI in wild boar of Saxony-Anhalt for the basic as well as the censored and adjusted dataset.

\begin{tabular}{lccccc}
\hline Data set & $\begin{array}{c}\text { Time } \\
\text { interval }\end{array}$ & $\begin{array}{c}\text { Sample } \\
\text { size }\end{array}$ & $\begin{array}{c}\text { Prevalence } \\
(\%)\end{array}$ & $\begin{array}{c}\text { LCL }^{\mathrm{a}} \\
(\%)\end{array}$ & $\begin{array}{c}\mathrm{UCL}^{\mathrm{b}} \\
(\%)\end{array}$ \\
\hline Basic & 1 & 3,605 & 4.47 & 3.79 & 5.14 \\
& 2 & 3,604 & 9.05 & 8.11 & 9.98 \\
Censored/adjusted & 1 & $823^{\mathrm{c}}$ & 3.60 & 2.67 & 4.62 \\
& 2 & $823^{\mathrm{c}}$ & 7.41 & 6.08 & 8.87 \\
\hline
\end{tabular}

${ }^{a} \mathrm{LCL}=$ lower confidence limit ${ }^{\mathrm{b}} \mathrm{UCL}=$ upper confidence limit

'Randomly sampled in each cycle from 3,605 (interval 1: January 2000-March 2009) and 3,604 (interval 2: March 2009December 2011) samples of the basic dataset, respectively. 
to assure a minimum sample density. Most of the locations with at least one positive sample were situated east of the rivers Elbe and Saale (Fig. 2).

\section{Evaluation of spatial variation in $R R$}

Notably, in both time intervals, the RR of a wild boar being seropositive for ADV was unevenly distributed in the study area with significantly higher numbers $(\mathrm{P}=0.05)$ in the triangular border area to the neighbouring federal states of Brandenburg and Saxony in the east of Saxony-Anhalt, where values close to $\mathrm{RR}=8.0$ and $\mathrm{RR}=4.5$ in intervals 1 and 2, respectively, were reached (Fig. 3). For time interval 2 , the area with an increased RR showed a tendency of expansion predominantly to the north. For both time intervals, the clusters $(\mathrm{P}=0.001)$ identified by the spatial scan test were almost congruent with the areas of significantly increased RR according to Hazelton and Davies (2009). The RRs (inside cluster versus outside cluster) of the clusters as determined by the scan statistic were $R R=41.2$ (interval 1 ) and $\mathrm{RR}=18.5$ (interval 2), respectively. Additional foci of disease were consistently found in the north (an isolated focus) and in the very south of the state in both time intervals. In time interval 2 , isolated positive samples were also found in the western part of the state.

\section{Spatial shift in ADV infection}

The dispersion and position of the adjusted differences between the first-level centroids of both time intervals relative to the null vector (axis origin) and the estimated mean shift vector, given by the difference between the axis origin and the (second-level) centroid of the dispersion of the differences between first-level centroids (Fig. 4), indicated a net spatial shift in ADV seropositive wild boar of $9.4 \mathrm{~km}$ in a north to northwesterly direction during the observation period. If the total shift distance $(9.4 \mathrm{~km})$ was divided by the difference between the medians of time intervals 1 and 2, respectively $\left(25^{\text {th }}\right.$ and $75^{\text {th }}$ percentiles of the basic dataset, see Fig. 1, 2.9 years), a mean shift distance of $3.3 \mathrm{~km}$ per year could be deduced. Given the data, the probability $\mathrm{P}$ for the null hypothesis that there was no shift in the centroid of ADV infection between time interval 1 and time interval 2 is 0.079 .

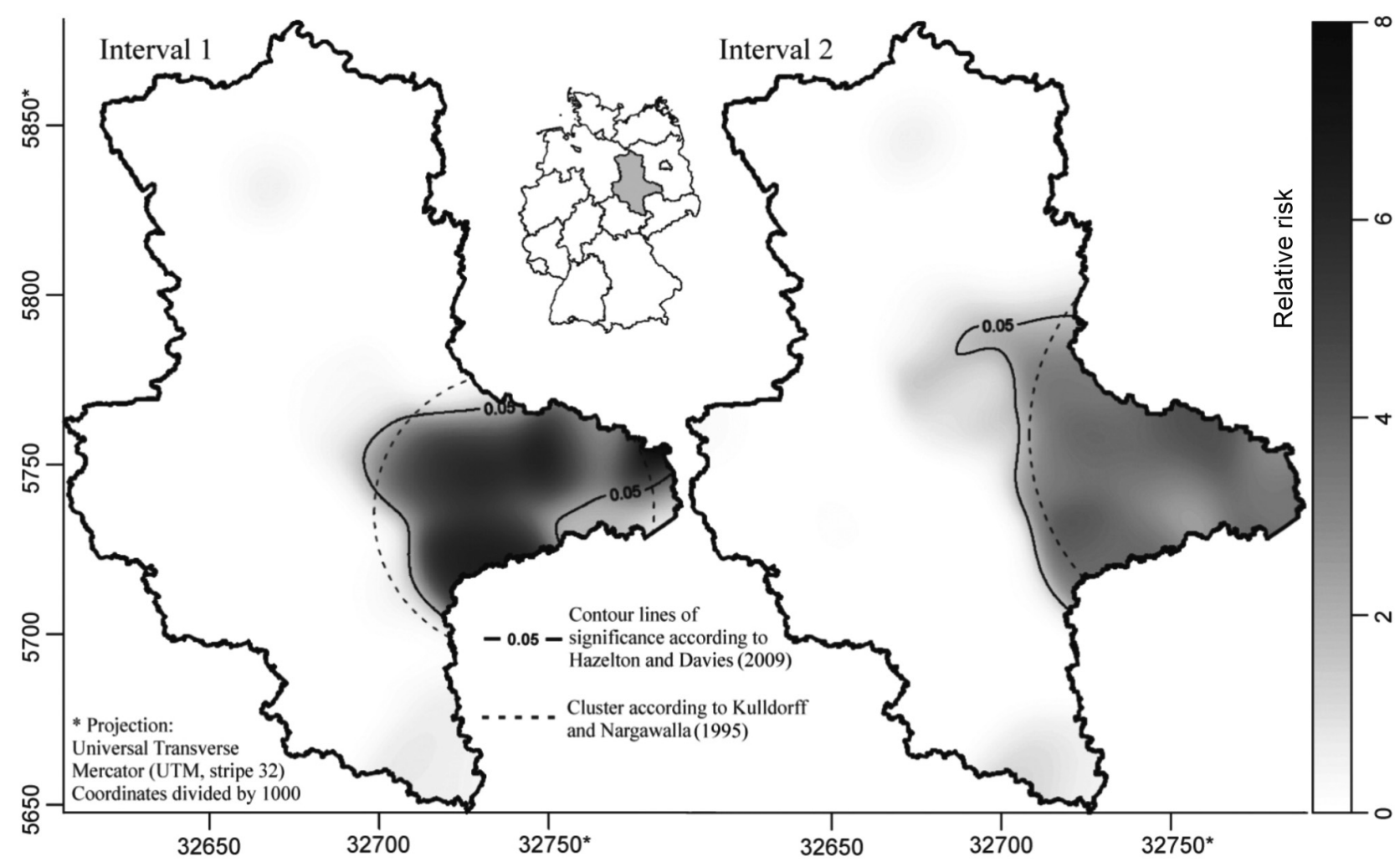

Fig. 3. Relative risk of a wild boar to test ADV seropositive and location of clusters for time interval 1 (January 2000-March 2009) and time interval 2 (March 2009-December 2011). 


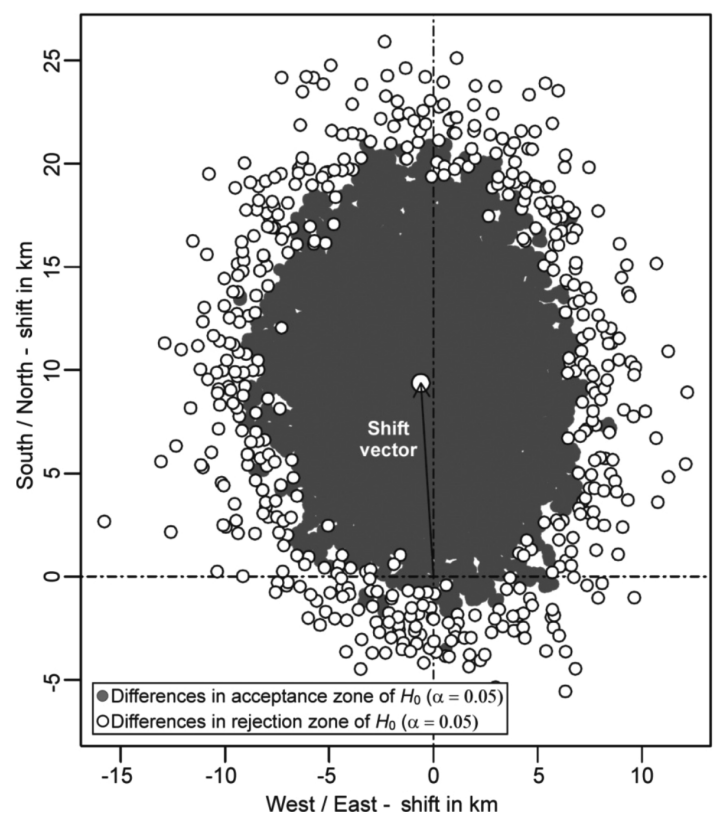

Fig. 4. Mean shift in centroid of ADV infection from time interval 1 to time interval 2. Differences between first-level centroids located in the densest $95 \%$ of the dispersion (in grey) and complementary differences in the rejection zone (in white) are depicted. The former represent the acceptance zone $(95 \%)$ of the null hypothesis with a significance level set to $\alpha=0.05$. The null vector is located in the acceptance zone of the null hypothesis but quite close to the rejection zone.

\section{Discussion}

A recent descriptive, epidemiological study revealed a steady, temporal increase in ADV seroprevalence in wild boar populations from East Germany, from $0.4 \%$ in 1985 to $15.9 \%$ in 2008 (Pannwitz et al., 2012). Whilst it could be demonstrated that in four out of the six federal states included in this comprehensive study (i.e. Mecklenburg-Western Pomerania, Brandenburg, Berlin and Saxony), ADV infections in wild boar populations occurred endemically throughout the entire territory, wild boar in the federal states of Saxony-Anhalt and Thuringia had so far only been affected in certain regions with large areas still uninfected. Serological evidence suggested that those two federal states became infected almost 15 years later than the previously-mentioned federal states, ostensibly representing the frontline of a continuing westward spread of ADV infection in wild boar populations in East Germany (Pannwitz et al., 2012).

For these reasons, Saxony-Anhalt represented an ideal study area to analyse the spatial development of ADV infections in more detail. In contrast to Pannwitz et al. (2012), we used an updated dataset comprising a time period of 12 years (2000-2011), including additional serological data from 2009-2011. A great advantage of the present study was that it was based on a dataset comprising an extremely large number of individual wild boar $(\mathrm{n}=7,209)$ for which geographical origin could be attributed to the lowest unit of territories available (subunits, see above) rather than on serological data aggregated at the municipality/district level. Using the centroids of those small subunits as surrogate point data in the spatial analysis bears a risk of bias, but this was balanced by them being the best approximation of the actual coordinates of sample origin. Additionally, considering the huge sample size and sound spatial distribution of the latter (Figs. 1 and 2), the net bias in the analyses was, however, assumed to be negligible.

The significant increase in the average ADV seroprevalence in the wild boar population of SaxonyAnhalt between the two defined time intervals (Fig. 1, Table 1) confirmed the overall trend in ADV seroprevalence as reported in East Germany for the past two and a half decades (Pannwitz et al., 2012). This was also substantiated using a censored and adjusted dataset to minimize the potential spatial selection bias related to the unevenly distributed RR of ADV infection in the territory, which resulted in seroprevalence estimates that were quite similar to those of the basic dataset (Table 1). For East Germany, a direct correlation between the hunting bag (as indicator of population density) of wild boar and ADV seroprevalence was found, suggesting that increasing population densities, as observed in Eastern Germany in recent decades (Müller et al., 2005), favour disease transmission and perpetuation of ADV among wild boar (Pannwitz et al., 2012). Hence, the increase in ADV seroprevalences in wild boar of Saxony-Anhalt could well be attributed to this effect alone. However, in addition, this state has a special situation by being situated on the western front of a large endemic area in Eastern Germany, which favours geographical spread of the disease from the neighbouring federal states Brandenburg and Saxony as well as within the state territory itself. The study demonstrates that antibodies to ADV are, so far, mainly found in the eastern part of SaxonyAnhalt. Within each of the two time intervals under investigation, the calculation of an RR surface with contour lines of significance as well as the spatial scan statistic revealed almost congruent areas with significantly increased RR. These areas were located in the east of the state in both time intervals. In the 
study, the absolute RR values of the scan statistic were generally higher than the maximum $R R$ values of the RR surface. This is because the scan statistic compares the ratio of all cases and population (all samples) within the cluster to the ratio of those outside the cluster, whereas the risk surface compares the risk in small grid cells $(250 \times 250 \mathrm{~m})$ with the average risk in all other grid cells, among which there are many others with high risk values within the clusters. However, both techniques indicated a relative reduction in the maximum $R R$ of the risk surface and the RR of the cluster detected by the scan statistic, respectively, from time interval 1 to time interval 2 of about $50 \%$. The disease had obviously spread from time interval 1 to time interval 2, levelling out the RR to a certain extent. In interval 2 particularly, the risk surface and contour lines of significance indicate that the area of increased RR has expanded slightly in the north-northwest direction. The dynamics outlined above have already been described for ADV in wild boar in an earlier study using data movies to visualise the spatial trend of seroprevalence, and were found to resemble a situation known as "emergence and dissolution of infection hotspots". This is characterised by a local cyclical accumulation of ADV seroprevalence in wild boar, with subsequent spread into non-infected areas followed by a rapid reduction in seroprevalence (Thulke et al., 2005).

To test the assumption of a spatial shift over time of ADV infection in wild boars (net spread in the entire territory) of Saxony-Anhalt, the time-dependent position of disease was defined as the centroid of the locations from which the specimen testing positive had originated. This approach implies that concentric expansions and compressions of the distribution pattern may not be detected but were not believed to be critical. Instead, a shift in terms of a translation (no rotation or reflection) with a summary directional vector differing from zero was assumed for the study area and thus was the focus of testing (Denzin et al., 2012). The uneven spatial distribution of the RR of wild boar in Saxony-Anhalt being infected with ADV (Fig. 3) required spatial segmentation of the data set and adjustment of sample densities per segment (grid cell) through segment-specific limitations of sample size in order to avoid a spatial selection bias. This was achieved in a stochastic procedure with samples being drawn in each iteration, inducing variability between iterations with regard to the observed centroids (Denzin et al., 2012). Despite this inevitable step, which actually reduced the power of the test approach, and the provision for a reduction in the sample size, even for the segment with the lowest sample density, by $\mathrm{k}=1$ to fulfill formal requirements of bootstrapping, a shift in the centroid of ADV seropositive wild boar in a north-northwestern direction significant at $\alpha=0.1$ was detected $(P=0.079)$, though the evidence was not sufficient to reject the null hypothesis at the more conservative significance level of $\alpha=0.05$. Thus, the direction of spread as deduced from the comparison of the RR surfaces and clusters in the east of the study area between time intervals (Fig. 3) could be confirmed as the net direction of spread for the entire territory of Saxony-Anhalt.

This is the first time an average speed of the spread of ADV infection in wild boar was attempted to be assessed. The obtained average speed of ADV spread of $3.3 \mathrm{~km}$ per year describes spread triggered by infection pressure from highly endemic areas east of the study area (Pannwitz et al., 2012) and, interestingly, is relatively similar to the shifts of 2.7 and 3.2 $\mathrm{km} / \mathrm{year}$ found for echinoccoosis in foxes for The Netherlands and Germany, respectively (Takumi et al., 2008; Denzin et al., 2012). Considering the relatively high mobility of wild boar, with home-range size and activity depending on sex, winter food availability and population density (Massei et al., 1997), this speed is surprisingly low. Whilst CSF virus, for example, is supposed to spread rapidly when introduced among susceptible wild boar (Artois et al., 2002), the observed low-speed spread of ADV in wild boar might be a result of the different nature and pathogenesis of this virus on the one hand and geographical features on the other hand. In contrast to highly contagious CSF virus (Artois et al., 2002), $\mathrm{ADV}$ variants circulating in wild boar seem to be perfectly host adapted (Pannwitz et al., 2012), resulting in more latent or subclinical infections with reduced virus excretion due to very low virulence (Müller et al., 2001, 2011). Only spontaneous reactivation results in the formation of infectious virions, which are shed and may infect adjacent susceptible animals (Mettenleiter et al., 2012). Additionally, ADV in wild swine is supposed to be primarily transmitted via the venereal route and not via the respiratory route, as is common in domestic swine (Romero et al., 1997). Furthermore, our study supports the assumption that in contrast to the situation in the neighbouring federal states to the east, at least for the time period under study, the spread of ADV in Saxony-Anhalt may have been hampered by natural barriers, i.e. the rivers Elbe and Saale. It seems as if the westward spreading ADV epidemic front (Pannwitz et al., 2012) was bouncing against the rivers Elbe and Saale, and so was partly 
diverted to the north (Fig. 2). Single positive sampling locations provide evidence, however, that the virus must have crossed the rivers already in time interval 1 but for unknown reasons did not spread further, still being stranded on the western banks of the rivers (Fig. 2). Interestingly, apart from the large cluster with significantly increased RR-values, there were two small, isolated foci of ADV disease in the northern and southern parts of the study area consistently found in both time intervals (Fig. 3). In time interval 2 a few positive samples were also detected in the western part of the study area (Fig. 2). Whilst the southern focus is most likely a result of infection pressure from adjacent areas in Saxony and Thuringia and belongs to the frontline of ADV infection as characterised above, the reasons for the other foci remain elusive, with single migrating wild boar being one possible explanation.

Presumably due to the high degree of host adaptation and the application of effective preventive measures for more than 25 years, no spill-over from wild boar to domestic pigs have been reported in Germany (Müller et al., 2011; Pannwitz et al., 2012). However, they cannot be completely ruled out in the future. Hence, in regions with evidence of the disease, the spatio-temporal trend of ADV infection in wild boar should be monitored and the findings should be appropriately communicated in order to foster compliance of pig holdings with biosecurity regulations and enable a risk-based control of the latter by the veterinary authorities.

The results obtained in this study prove that ADV infection in wild boar from Saxony-Anhalt forms part of the western front of a large-scale independent epidemic affecting Eastern Germany caused by a single ADV variant (Müller et al., 1998b, 2010; Pannwitz et al., 2012). Although at relatively low speed and obviously hampered and diverted by natural barriers, the epidemic is likely to approach the western neighbouring federal states. Therefore, and also because there is evidence of other foci of disease in western Germany, programmes concerning the monitoring of ADV infection in wild boar should be implemented in the western federal states as well. The activities of the federal states should in this field preferably be coordinated with respect to the requested sample size and sample information (also precision of the spatial information) in a nation-wide wildlife disease-monitoring programme. This would allow an evaluation involving the entire territory of Germany to apply the methods introduced for the federal state of SaxonyAnhalt.

\section{Acknowledgement}

This study is part of an on-going wild boar monitoring programme under the supervision of the Veterinary Service, Department 65, Ministry of Agriculture and Environment Saxony-Anhalt.

\section{References}

Albina E, Mesplède A, Chenut G, Le Potier MF, Bourbao G, Le Gal S, Leforban Y, 2000. A serological survey on classical swine fever (CSF), Aujeszky's disease (AD) and porcine reproductive and respiratory syndrome (PRRS) virus infections in French wild boars from 1991 to 1998. Vet Microbiol 77, 43-57.

Anonymous, 1987. Directive on enforcement of veterinary investigations for health monitoring of wild game of 4 August 1987. Ministerium fuer Land - und Forstwirtschaft, German Democratic Republic, Berlin, Germany.

Artois M, Depner KR, Guberti V, Hars J, Rossi S, Rutili D, 2002. Classical swine fever (hog cholera) in wild boar in Europe. Rev Sci Tech 21, 287-303.

Bithell J, 1990. An application of density estimation to geographical epidemiology. Stat Med 9, 691-701.

Bithell J, 1991. Estimation of relative risk function. Stat Med 10, 1745-1751.

Boadella M, Gortázar C, Vicente J, Ruiz-Fons F, 2012. Wild boar: an increasing concern for Aujeszky's disease control in pigs? BMC Vet Res 8, 7.

Bowman A, Azzalini A, 1997. Applied smoothing techniques for data analysis: the kernel approach with S-PLUS Illustrations, Oxford: Oxford University Press.

Cannon RM, Roe RT, 1982. Livestock disease surveys. A field manual for veterinarians. Canberra: Australian Government Publishing Service.

Davies TM, Hazelton ML, Marshall JC, 2011. Sparr: analyzing spatial relative risk using fixed and adaptive kernel density estimation in R. J Stat Softw 39, 1-14.

Denzin N, Schliephake A, Fröhlich A, Ziller M, Conraths FJ, 2012. On the move? Echinococcus multilocularis in red foxes of Saxony-Anhalt (Germany). Transbound Emerg Dis. Published online: 7 November 2012. doi:10.1111/tbed.12026.

Diggle PJ, 1985. A kernel method for smoothing point process data. J Roy Stat Soc C-App 34, 138-147.

Diggle PJ, Chetwynd AG, Haggkvist R, Morris SE, 1995. Second-order analysis of space-time clustering. Stat Methods Med Res 4, 124-136.

Gortázar C, Vicente J, Fierro Y, León L, Cubero MJ, González M, 2002. Natural Aujeszky's disease in a Spanish wild boar population. In: Domestic animal/wildlife interface: issue for disease control, conservation, sustainable food production, and emerging diseases. Gibbs EPJ, Bokma BH (eds). Ann NY Acad Sci, 210-212 pp. 
Hazelton ML, Davies TM, 2009. Inference based on kernel estimates of the relative risk function in geographical epidemiology. Biometrical J 51, 98-109.

Kaden V, Lange E, Hänel A, Hlinak A, Mewes L, Hergarten G, Irsch B, Dedek J, Bruer W, 2009. Retrospective serological survey on selected viral pathogens in wild boar populations in Germany. Eur J Wildl Res 55, 153-159.

Kulldorff M, Athas WF, Feurer EJ, Miller BA, Key CR, 1998. Evaluating cluster alarms: a space-time scan statistic and brain cancer in Los Alamos, New Mexico. Am J Public Health 88, 1377-1380.

Kulldorf M, Nargawalla N, 1995. Spatial disease clusters: detection and inference. Stat Med 14, 799-810.

Leuenberger R, Boujon P, Thür B, Miserez R, Garin-Bastuji G, Rüfenacht J, Stärk KD, 2007. Prevalence of classical swine fever, Aujeszky's disease and brucellosis in a population of wild boar in Switzerland. Vet Rec 160, 362-368.

Massei G, Genov PV, Staines BW, Gorman ML, 1997. Factors influencing home range and activity of wild boar (Sus scrofa) in a Mediterranean coastal area. J Zool 242, 411-423.

Mettenleiter TC, 2000. Aujeszky's disease (pseudorabies) virus: the virus and molecular pathogenesis. Vet Res 31, 99-115.

Mettenleiter TC, Ehlers B, Müller T, Yoon KJ, Teifke JP, 2012. Herpesviruses (Aujeszky's disease virus, porcine cytomegalovirus, porcine lymphotropic herpesviruses, malignant catarrhal fever virus). In: Diseases of swine. Zimmerman J, Karriker L, Ramirez A, Schwartz K, Stevenson G (eds). Chichester: John Wiley \& Sons, 412-444 pp.

Müller T, Bätza HJ, Schlüter H, Conraths FJ, Mettenleiter TC, 2003. Eradication of Aujeszky's disease in Germany. J Vet Med B 50, 207-213.

Müller T, Conraths FJ, Hahn EC, 2000. Pseudorabies virus infection (Aujeszky's disease) in wild swine. Infect Dis Rev 2, 27-34.

Müller T, Hahn EC, Tottewitz F, Kramer M, Klupp BG, Mettenleiter TC, Freuling C, 2011. Pseudorabies virus infections in wild swine - a global perspective. Arch Virol 156, 1691-705.

Müller T, Klupp B, Zellmer R, Teuffert J, Ziedler K, Possardt C, Dresenkamp B, Conraths FJ, Mettenleiter TC, 1998b. Characterisation of pseudorabies virus isolated from wild boar (Sus scrofa). Vet Rec 143, 337-340.

Müller T, Klupp BG, Freuling C, Hoffmann B, Mojcicz M, Capua I, Palfi V, Toma B, Lutz W, Ruiz-Fon F et al., 2010. Characterization of pseudorabies virus of wild boar origin from Europe. Epidemiol Infect 138, 1590-1600.

Müller T, Teuffert J, Staubach C, Selhorst T, Depner KR, 2005. Long-term studies on maternal immunity for Aujeszky's disease and classical swine fever in wild boar piglets. J Vet Med B 52, 432-436.

Müller T, Teuffert J, Zellmer R, Conraths FJ, 2001. Experimental infection of European wild boars and domestic pigs with pseudorabies viruses with differing virulence. Am J Vet Res 62, 252-258.

Müller T, Teuffert J, Zellmer R, Staubach C, Klupp B, Otte MJ, Conraths FJ, 1997. Pseudorabies virus infections in european wild boar - a potential danger for domestic pigs? Epidemiol Sante Anim 31-33, 97-99.

Müller T, Teuffert J, Ziedler K, Possardt C, Kramer M, Staubach C, Conraths FJ, 1998a. Pseudorabies in the European wild boar from eastern Germany. J Wildl Dis 34, 251-258.

Oren SL, Swenson SL, Kinker DR, Hill HT, Hu HL, Zimmermann J, 1993. Evaluation of serological pseudorabies tests for the detection of antibodies during early infection. J Vet Diagn Invest 5, 529-533.

Oslage U, Dahle J, Müller T, Kramer M, Beier D, Liess B, 1994. Prevalence of antibodies against the viruses of european swine fever, Aujeszky's disease and "porcine reproductive and respiratory syndrome" in wild boars in the federal states SachsenAnhalt and Brandenburg. Deut Tierarztl Woch 101, 33-38.

Pannwitz G, Freuling C, Denzin N, Schaarschmidt U, Nieper H, Hlinak A, Burkhardt S, Klopries M, Dedek J, Hoffmann L et al., 2012. A long-term serological survey on Aujeszky's disease virus infection in wild boar in East Germany. Epidemiol Infect 140, 348-358.

Pensaert MB, Kluge JP, 1989. Pseudorabies virus (Aujeszky's disease). In: Virus infections of porcines. Pensaert MB (ed). Elsevier, 39-64 pp.

Petrie A, Watson P, 2006. Statistics for veterinary and animal science Oxford: Blackwell Publishing.

R Development Core Team, 2011. R: a language and environment for statistical computing. Vienna: R Foundation for Statistical Computing.

Roic B, Jemersic L, Terzic S, Keros T, Balatinec J, Florijancic T, 2012. Prevalence of antibodies to selected viral pathogens in wild boars (Sus scrofa) in Croatia in 2005-06 and 2009-10. J Wildl Dis 48, 131-137.

Romero CH, Meade P, Santagata J, Gillis K, Lollis G, Hahn EC, Gibbs EP, 1997. Genital infection and transmission of pseudorabies virus in feral swine in Florida, USA. Vet Microbiol 55, 131-139.

SaTScan. Available at: http://www.satscan.org (accessed on October 2013).

Sattler T, Sailer E, Wodak E, Schmoll F, 2012. Serological detection of emerging viral infections in wild boars from different hunting regions of Southern Germany. Tierarztl Prax 40, 27-32. Sedlak K, Bartova E, Machova J, 2008. Antibodies to selected viral disease agents in wild boars from the Czech Republic. J Wildl Dis 44, 777-780.

Shcherbakov AV, Kukushkin SA, Timina AM, Baibikow TZ, Kovalishin VF, Kanshina AV, Biadovskaia OP, Prokhvatilova LB, Ruchnova OI, Bakunov IN et al., 2007. Monitoring of infectious diseases among wild boars. Vop Virusol 52, 29-33. 
Silverman B, 1986. Density estimation for statistics and data analysis. London: Chapman and Hall.

Steinrigl A, Revilla-Fernández S, Kolodziejek J, Wodak E, Bagó Z, Nowotny N, Schmoll F, Köfer J, 2012. Detection and molecular characterization of Suid herpesvirus type 1 in Austrian wild boar and hunting dogs. Vet Microbiol 157, 276-284.

Szweda W, Lipowski A, Ciecierski H, Zalewski K, Pirus T, 1998. European wild boar (Sus scrofa L.) as a reservoir of Herpesvirus suis 1. Med Weter 54, 541-544.

Takumi K, de Vries A, Chu ML, Mulder J, Teunis P, van der Giessen J, 2008. Evidence for an increasing presence of Echinococcus multilocularis in foxes in The Netherlands. Int J
Parasitol 38, 571-578.

Thulke HH, Selhorst T, Müller T, 2005. Pseudorabies virus infection in wild boar: data visualisation as an aid to understanding disease dynamics. Prev Vet Med 68, 35-48.

Vengust G, Valencak Z, Bidovec A, 2006. A serological survey of selected pathogens in wild boar in Slovenia. J Vet Med 53, 24-27.

Zupancic Z, Jukic B, Lojkic M, Cac Z, Jemersic L, Staresina V, 2002. Prevalence of antibodies to classical swine fever, Aujeszky's disease, porcine reproductive and respiratory syndrome, and bovine viral diarrhoea viruses in wild boars in Croatia. J Vet Med 49, 253-256. 